\title{
Adrenaline, cardiac arrest, and evidence based medicine
}

\author{
Timothy H Rainer, Colin E Robertson
}

\begin{abstract}
Adrenaline has been used for over a century in the experimental resuscitation of animals following cardiac arrest. ${ }^{1}$ Its use in humans was proposed as early as $1896 .^{2}$ It features as the primary pharmacological agent in the current European (ERC) and North American (AHA) guidelines for the management of cardiac arrest in adults and children. ${ }^{3-5}$ Despite these recommendations, there is doubt about the efficacy of adrenaline in this situation. "Evidence based medicine" is demanded increasingly by clinicians for current and future treatments. ${ }^{6}$ In this article we summarise the pharmacology and mechanisms of action of adrenaline, and review its use and value in cardiac arrest.
\end{abstract}

\section{Endogenous catecholamine responses in cardiac arrest}

Adrenaline is released from the adrenal medulla and sympathetic nerve terminals throughout the vascular system. Conditions such as trauma, hypotension, sepsis, and hypoglycaemia increase circulating concentrations of adrenaline and other catecholamines, producing increases in cardiac rate, contractility, and systemic vascular resistance. ${ }^{7}$ The highest endogenous concentrations of adrenaline occur in cardiac arrest. ${ }^{8}$ Despite these grossly elevated levels, their further augmentation appears to have beneficial haemodynamic effects. ${ }^{9}$

Adrenergic receptors have been found in many tissues including the heart, brain, and vascular system. Catecholamines such as adrenaline mediate their actions by stimulating these receptors, and two specific types have been demonstrated. Within these types, further differentiation into $\alpha_{1}, \alpha_{2}, \beta_{1}, \beta_{2}$, and $\beta_{3}$ subtypes exist. ${ }^{1011}$

Stimulation of $\alpha_{1}$ and $\alpha_{2}$ receptors causes vasoconstriction of arterial resistance vessels and venous capacitance vessels. In the beating heart, $\beta_{1}$ receptor stimulation increases heart rate and contractility, and in the fibrillating heart may increase the frequency and amplitude of the fibrillating waveform. ${ }^{12}$ Stimulation of $\beta_{2}$ receptors causes vascular and respiratory tract smooth muscle relaxation and hence vasodilatation and bronchodilatation, and may also reduce the threshold for defibrillation. ${ }^{13} 14$

Adrenaline shows $\alpha_{1}, \alpha_{2}, \beta_{1}$, and $\beta_{2}$ activity when given during cardiac arrest. The relative contributions made by stimulation of these receptors and their subtypes is important and will influence factors such as coronary and cerebral perfusion. The effect of stimulation of these receptors depends upon their number and tissue density, functional state ("up- and downregulation"), and accessibility to the agent. $^{1}$

\section{Mechanisms producing perfusion during} cardiopulmonary resuscitation

Closed chest cardiopulmonary resuscitation (CPR), at best, produces approximately one third of the normal cardiac output of the spontaneously beating heart. ${ }^{15}$ Thus a primary goal of CPR is to produce a return of spontaneous circulation. In its absence, and hopefully pending its return, efforts to maximise cardiac output during CPR are crucial to improving myocardial and cerebral perfusion.

Myocardial blood flow, and hence the heart's viability, is related to the coronary perfusion pressure. This is the difference between aortic diastolic pressure and the right atrial pressure. In animals and humans, coronary perfusion pressure levels correlate well with successful defibrillation and return of spontaneous circulation. ${ }^{10} 16$ During spontaneous circulation there are differences in the flow between the epicardial and intramyocardial arteries. At higher aortic pressures the phasic differences in coronary blood flow are small. At normal or lower arterial pressures, antegrade flow persists through the larger epicardial vessels during systole, although there is retrograde flow through the intramyocardial vessels preventing coronary filling. Perfusion of the intramyocardial vessels therefore occurs during diastole at lower arterial pressures. At higher pressures it continues during systole. ${ }^{17}$ In cardiac arrest, the difference between aortic diastolic pressure and right atrial pressure is still important, but the mechanisms producing this differ from those of spontaneous circulation. Coronary perfusion occurs during the relaxation phase of chest compression in CPR rather than diastole as in the beating heart. During CPR, right atrial pressure is relatively constant; hence myocardial perfusion reflects changes in aortic diastolic pressure.

Cerebral function and preservation depend on cerebral perfusion. Since the brain's autoregulatory ability is poor, especially in states of low systemic flow such as are found in cardiac arrest, cerebral perfusion is directly 
influenced by cardiac output. ${ }^{15} 18$ Cerebral perfusion depends upon the gradient between arterial and venous pressures and will also be affected by factors influencing intracranial pressure. Thus, in contrast to the heart, cerebral perfusion occurs during the compression or "systolic" phase of the CPR cycle. Furthermore, the longer the downtime from onset of cardiac arrest to initiation of bystander CPR the poorer the cerebral perfusion. ${ }^{15}$

Haemodynamic effects in animal studies Since controlled human studies investigating the mechanisms of action of adrenaline in cardiac arrest are impossible, our knowledge is principally derived from animal models. ${ }^{1019-21}$ From these studies it is clear that adrenaline improves the global haemodynamic state in cardiac arrest by increasing systemic vascular resistance (thus increasing aortic diastolic pressure) and altering patterns of regional blood flow, directing blood preferentially to the heart and brain. These actions are dose dependent. With increasing doses, parallel increases can be demonstrated in aortic diastolic pressure, myocardial blood flow and oxygen consumption, and cerebral cortical and brainstem flow. These actions are mirrored by improved rates of outcome parameters such as return of spontaneous circulation and survival. ${ }^{10}$

The efficacy of adrenaline may be further affected by its method of administration. It may be introduced intravenously through a peripheral or central vein, by intracardiac injection, or endobronchially, and this may be followed by a method of dispersion such as a bolus of fluid or rapid repeated ventilations. When adrenaline is given exogenously higher arterial concentrations are achieved than can be attained through endogenous production, and when it is given early after the induction of cardiac arrest it has an impact on immediate resuscitability. ${ }^{22}$

The extrapolation of animal data to the human clinical situation is, however, fraught with problems. Humans have unique physiological, anatomical, and receptor characteristics, and experimental animals are not usually affected by the principal disease process that leads to adult human cardiac arrest - ischaemic heart disease.

Haemodynamic effects in human studies Adrenaline increases systemic pressures achieved during CPR in a dose dependent fashion, and as a result improves coronary perfusion pressure. ${ }^{16}{ }^{23}$ However, potentially deleterious haemodynamic effects include coronary vasoconstriction and postresuscitation arterial hypertension. ${ }^{19}$

Adrenaline is thought to augment cerebral blood flow by shunting blood from nonessential organs and increasing carotid arterial pressure, with redistribution towards the cerebrum. It may also improve cerebral perfusion by resisting the tendency of the intrathoracic portion of the carotid artery to collapse. $^{2425}$

\section{Adrenaline and electrical responses}

In cardiac arrest, electrical activity may broadly be divided into three groups: ventricular fibrillation/tachycardia (VF/VT), asystole, and electromechanical dissociation (EMD). Without treatment and with the passage of time, the VF waveform decreases in amplitude and frequency. These changes are accompanied by reduction in the probability of successful defibrillation and relate to the depletion of myocardial high energy phosphate stores. ${ }^{15}$

ANIMAL AND HUMAN STUDIES

Adrenaline increases the frequency and amplitude of the VF waveform by $\beta_{2}$ receptor stimulation. ${ }^{12}$ However, this has not been shown to improve the chances of successful defibrillation, either in healthy hearts ${ }^{20}$ or in those following coronary occlusion. ${ }^{27} 28$ Few human studies have documented changes in the amplitude and frequency of the fibrillatory waveform either with different doses of adrenaline or placebo, although marked coarsening in VF followed the administration of high dose adrenaline in one patient. ${ }^{29}$

\section{Adrenaline and CPR outcome}

In the past, comparison and evaluation of outcomes from published reports have been difficult because of a lack of standardisation in the reporting of results.

ANIMAL STUDIES

Most animal studies concentrate upon the haemodynamic effects of adrenaline in cardiac arrest. Outcomes are usually expressed as survival for minutes or hours. An improvement in these indices has been demonstrated following the administration of adrenaline. ${ }^{15}$ However, few studies report on survival to 24 hours or longer. Thus it is uncertain if the improvement in haemodynamic status is matched to long term survival.

\section{HUMAN STUDIES - STANDARD DOSE $V$ HIGH} DOSE

If improved haemodynamics lead to more favourable outcomes this would be expected to be manifest by a dose-response effect. However, demonstrating this effect has proved difficult. Early anecdotal reports using "high" doses (5-10 mg; HD) of adrenaline suggested beneficial effects on survival and led various groups to investigate the comparative effect of different doses of adrenaline upon outcome. ${ }^{29-31}$

The first prospective, randomised trials compared HD and standard dose (SD) adrenaline and showed an improvement in resuscitation rates, but the number of patients studied was small, and the power of the studies limited. ${ }^{32} 33$

Three large prospective randomised North American trials have been published. One (prehospital) study showed a significant improvement in early outcome measures ${ }^{34}$ and a non-significant trend towards greater discharge rates with high dose adrenaline. However, trends in cerebral performance categories were worse with the higher dose. 
There was no significant difference in the duration of hospital or critical care unit stays. The other two studies did not show any significant improvement in return of spontaneous circulation, resuscitation rates, admission or discharge rates, or neurological outcome with high dose adrenaline. ${ }^{35} 36$

A recent French trial confirmed no improvement in return of spontaneous circulation or admission rates and at six months could show no significant difference in survival between HD and SD. ${ }^{37}$ While neither adverse cardiac nor neurological effects were noted, the number of long term survivors was very small.

HUMAN STUDIES - STANDARD DOSE $V$ PLACEBO/ NO DOSE

Few studies have compared adrenaline versus placebo. Most were non-randomised, uncontrolled studies - and few have looked at adrenaline as the main study intervention. ${ }^{38-42}$ Some look only at groups with a recognised poor prognosis, that is, asystole ${ }^{34}$ or electromechanical dissociation. ${ }^{42}$ Only one study recorded return of spontaneous circulation as an outcome variable. ${ }^{38}$ In this uncontrolled trial a better outcome was found in those patients who did not receive adrenaline.

Of the in-hospital studies, none was controlled and none found improvement in discharge rates associated with adrenaline. ${ }^{38-41}$ Two showed a significantly better outcome following placebo/no drug. ${ }^{39} 41$

The data from prehospital studies ${ }^{42-44}$ comparing adrenaline and placebo are even scantier, but one study showed a trend towards improved survival in those not receiving adrenaline. Although all these studies are prospective, the study with the greatest power was not randomised and investigated a group with a poor prognosis. ${ }^{44}$

While the methodologies of most of these studies are not ideal - retrospective or descriptive, with no predetermined control or randomisation - the evidence to date suggests that, if anything, adrenaline has a detrimental effect on outcome.

\section{Conclusion: where do we go from here?}

Despite the fact that the use of adrenaline in cardiac arrest has been hallowed by time, and that it is the drug of choice in both ERC and AHA guidelines, there is a lack of evidence that it improves outcome. High dose adrenaline provides no additional benefit over standard dose regimens, and pending the results of definitive studies on standard dose $v$ placebo a healthy scepticism is warranted. The first prospective, randomised, double blind controlled trial comparing adrenaline with placebo has recently been published. ${ }^{45}$ The study numbers were small and there were no differences in discharge survival. If there are any benefits of adrenaline on overall survival following cardiac arrest they appear to be slight, although it is possible that in certain subgroups of patients the benefit may be more marked. In the meantime the importance of basic life support and prompt defibrillation in the treatment of cardiac arrest cannot be overemphasised.

\section{Summary}

In this article we review the evidence supporting the clinical application of adrenaline in cardiopulmonary arrest, and summarise the receptor effects of catecholamines and the basic principles producing perfusion during CPR. Animal and human studies show that in cardiac arrest, adrenaline has positive haemodynamic effects, increasing systemic pressures, myocardial perfusion, and cerebrally directed flow. The problems extrapolating from animal to human data are highlighted. Studies showing improvements in short term survival outcomes with high dose regimens have not been confirmed by other large prospective randomised trials. There is no evidence that high doses of adrenaline improve survival to hospital discharge. Most studies comparing adrenaline with placebo have been non-randomised and uncontrolled, with major methodological problems. Conclusions are difficult, but if anything adrenaline is associated with poorer outcomes.

1 Paradis NA, Koscove EM. Epinephrine in cardiac arrest: a critical review. Ann Emerg Med 1990;19:1288-301.

2 Gottlieb R. Ueber die wirkung der nebennierenextract auf herz und blutdruck. Arch Exp Pathol Pharmakol 1896; 38:99-112.

3 Advanced Life Support Working Party of the European Resuscitation Council. Guidelines for advanced lif support. Resuscitation 1992;24:11-122.

4 Paediatric Life Support Working party of the European Resuscitation Council. Guidelines for paediatric life support. Resuscitation 1994;27:91-105.

5 Emergency cardiac care committee and subcommittees, American Heart Association. Guidelines for cardiopulmonary resuscitation and emergency cardiac care. ҰAMA 1992;268:2199-241.

6 Morrison I, Smith R. The future of medicine. $B M F$ 1994;309:1099-100.

7 Kern KB, Elchisak MA, Sanders AB, Badylak SF, Tacker WA, Ewy GA. Plasma catecholamines and resuscitation from prolonged cardiac arrest. Crit Care Med 1989; 17:786-91.

8 Wortsman J, Frank S, Cryer FE. Adrenomedullary response to maximal stress in humans. Am $f$ Med 1984;77: to maxima

9 Schoffstall JM, Spivey WH, Davidheiser S, Fuhs L, Kirkpatrick R. Endogenous and exogenous plasma catecholamine levels in cardiac arrest in swine. Resuscitation 1990;19:241-51.

10 Bleske BE, Billi JE. Comparison of adrenergic agonists for the treatment of ventricular fibrillation and pulseless electrical activity. Resuscitation 1994;28:239-51.

11 Wheeldon NM, McDevitt DG, Lipworth BJ. Investigation of putative cardiac $\beta 3$-adrenoceptors in man. $Q \mathcal{F} \mathrm{Med}$ 1993;86:255-61.

12 Livesay J, Folette DM, Fey KH, Nelson RL, De Land EC Barnard RJ, et al. Optimising myocardial supply/demand balance with alpha-adrenergic drugs during cardiopulmonary resuscitation. 7 Thorac Cardiovasc Surg 1978 76:244-51.

13 Ruffy R, Schechtman K, Monje E. B-Adrenergic modulation of direct defibrillation energy in anaesthetised dog heart. Am ₹ Physiol 1985;248:H674-7.

14 Ruffy R, Schechtman K, Monje E, Sandza J. Adrenergically mediated variations in the energy required to defibrillate the heart: observations in closed-chest, nonanaesthetised the heart: observations in closed-che
dogs. Circulation 1986;73:374-80.

15 Brown CG, Werman HA. Adrenergic agonists during cardiopulmonary resuscitation. Resuscitation 1990;19: $1-16$.

16 Paradis NA, Martin GB, Rivers EP, Goetting MG Appleton TJ, Feingold $M$, et al. Coronary perfusion pressure and the return of spontaneous circulation in human cardiopulmonary resuscitation. $\mathscr{f} A M A \quad 1990$ 263:1106-13

17 Chillian WM, Marcus ML. Effects of coronary and extravascular pressure on intramyocardial and epicardial blood velocity. $A m \mathcal{F}$ Physiol 1992;248: H170-8.

18 Wolfson SK, Safar P, Reich H, Clark JM, Gur D, Stezoski $\mathrm{W}$, et al. Dynamic heterogeneity of cerebral hypoperfusion after prolonged cardiac arrest in dogs measured by the stable xenon/CT technique: a preliminary study. Resuscitation 1992;23:1-20. 
19 Linder KH, Koster R. Vasopressor drugs during cardiopulmonary resuscitation. Resuscitation 1992;24:147-54.

20 Waller DG, Robertson CE. Role of sympathomimetic amines during cardiopulmonary resuscitation. Resuscitation 1991;22:181-90.

21 Brown CG, Birinyi F, Werman HA, Davis EA, Hamlin RL. The comparative effects of epinephrine versus phenylephrine on regional cerebral blood flow during cardiopulmonary resuscitation. Resuscitation 1986;14: 171-83.

22 Hornchen U, Schuttler J, Stoeckel H. Influence of the pulmonary circulation on adrenaline pharmacokinetics during cardiopulmonary resuscitation. Eur $\mathcal{f}$ Anaesthesiol during cardiopulm

23 Gonzalez ER, Ornato JP, Garnett AR, Levine RL, Rach EM. Dose-dependent vasopressor response to epin-
ephrine during CPR in human beings. Ann Emerg Med $1989 ; 18: 920-6$

24 Yin FCP, Cohen JM, Tsitlik J, Zola B, Weisfeldt ML. Role of carotid artery resistance to collapse during highintrathoracic-pressure CPR. Am f Physiol 1982;12: H259-67.

25 Brown CG, Taylor RB, Werman HA, Luu T, Hamlin RL. Carotid artery collapse during CPR - the importance of cardiac versus thoracic pump mechanisms demonstrated with cineangiography. Ann Emerg Med 1987; 16:513.

26 Yakaitis RW, Ewy GA, Otto CW, Taren DL, Moon TE. Influence of time and therapy on ventricular defibrillation in dogs. Crit Care Med 1980;8:157-63.

27 Otto CW, Yakaitis RW, Ewy GA. Spontaneous ischemic ventricular fibrillation in dogs: a new model for the study of cardiopulmonary resuscitation. Crit Care Med of cardiopulm

28 Otto CW, Yakaitis RW, Ewy GA. Effect of epinephrine on defibrillation in ischemic ventricular fibrillation. $A m$ Emerg Med 1985;3:285-91.

29 Koskove EM, Paradis NA. Successful resuscitation from cardiac arrest using high-dose epinephrine therapy. FAMA 1988;259:3031-4.

30 Cipolotti G, Paccagnella A, Simini G. Successful cardiopulmonary resuscitation using high doses of epinephrine. Int $\mathcal{F}$ Cardiol 1991;33:430-1.

31 Chin DT, Vincent R, Bagg RL. Adrenaline-responsive electromechanical dissociation. Resuscitation 1994;27: 215-9.

32 Barton C, Callaham M. High-dose epinephrine improves the return of spontaneous circulation rates in human victims of cardiac arrest. Ann Emerg Med 1991;20:722-5.
33 Lindner KH,Ahnfield FW, Prengel AW. Comparison of standard and high-dose adrenaline in the resuscitation of asystole and electromechanical dissociation. Acto Anaesthesiol Scand 1991;35:253-6.

34 Callaham M, Madsen CD, Barton CW, Saunders CE, Pointer J. A randomised clinical trial of high-dose epinephrine and norepinephrine vs standard-dose epinephrine in prehospital cardiac arrest. $\mathfrak{f} A M A$ 1992;21:2667-72.

35 Stiell IG, Herbert PC, Weitzman BN, Wells GA, Raman S, Stark RM, et al. High-dose epinephrine in adult cardiac arrest. $N$ Engl f Med 1992;327:1045-50.

36 Brown CG, Martin DR, Pepe PE, Steuven H, Cummins RO, Gonzalez E, et al and the Multicenter High-dose Epinephrine Study Group. A comparison of standardEpinephrine Study Group. A comparison of standardhospital. $N$ Engl $\mathcal{F}$ Med 1992;327:1051-5.

37 Choux C, Gueugniaud P-Y, Barbiuex A, Pham E, Lae C, Dubien P-Y, et al. Standard doses versus repeated high doses of epinephrine in cardiac arrest outside the hospital. Resuscitation 1995;29:3-9.

38 Marwick TH, Case C, Sisking V, Woodhouse SP. Adverse effect of early high-dose adrenaline on outcome of ventricular fibrillation. Lancet 1988;ii:66-8.

39 Beuret P, Feihl F, Vogt P, Perret A, Romand J-A, Perret C. Cardiac arrest: prognostic factors and outcome at one year. Resuscitation 1993;25:171-9.

40 Tortolani AJ, Risucci DA, Powell SR, Dixon R. In-hospital cardiopulmonary resuscitation during asystole: therapeutic factors associated with 24 hour survival. Chest 1989;96:622-6.

41 Roberts D, Landolfo K, Light RB, Dobson K. Early predictors of mortality for hospitalised patients suffering predictors of mortality for hospitalised patients suffering

42 Weaver WD, Fahrenbruch CE, Johnson DD, Hallstrom AP Cobb LA, Copass MK. Effect of epinephrine and lidocaine therapy on outcome after cardiac arrest due to lidocaine therapy on outcome after cardiac arrest due

43 Woodhouse SP, Lewis-Driver D, Eller H. Catecholamines during cardiopulmonary resuscitation for cardiac arrest Resuscitation 1992;24:263-72.

44 Herlitz J, Ekstrom L, Wennerblom B, Axelsson A, Bang A Holmberg S. Survival among patients with out-of-hospita cardiac arrest found in electromechanical dissociation. Resuscitation 1995;29:97-106.

45 Woodhouse SP, Cox S, Boyd P, Case C, Weber M. High dose and standard dose adrenaline do not alter survival, compared with placebo, in cardiac arrest. Resuscitation 1995;30:243-9.

Conference Secretariat, Emergency Nurses Association of NSW

PO Box 953, Parramatta, NSW, Australia 2124

Tel/fax: + 6126884937 or + 6147332400 